University at Albany, State University of New York

Scholars Archive

$9-2020$

\title{
Can You See Me Now?: Engaging Distance Learners Through Virtual Reference Consultations
}

\author{
Lauren Puzier \\ University at Albany, State University of New York, Ipuzier@albany.edu \\ Camille Chesley \\ University at Albany, State University of New York, cchesley@albany.edu \\ Amanda M. Lowe \\ University at Albany, State University of New York, amlowe@albany.edu
}

Follow this and additional works at: https://scholarsarchive.library.albany.edu/ulib_fac_scholar

Part of the Disability and Equity in Education Commons, Higher Education Commons, Library and Information Science Commons, Marketing Commons, and the Online and Distance Education Commons

\section{Recommended Citation}

Puzier, Lauren; Chesley, Camille; and Lowe, Amanda M., "Can You See Me Now?: Engaging Distance Learners Through Virtual Reference Consultations" (2020). University Libraries Faculty Scholarship. 133. https://scholarsarchive.library.albany.edu/ulib_fac_scholar/133

This Article is brought to you for free and open access by the University Libraries at Scholars Archive. It has been accepted for inclusion in University Libraries Faculty Scholarship by an authorized administrator of Scholars Archive. For more information, please contact scholarsarchive@albany.edu. 


\begin{abstract}
Research consultations continue to be a valuable service offered by academic libraries for students who are able to visit the library, however, most students enrolled in online degree programs or considering enrollment have limited access to campus services. To address this, the authors designed and tested a virtual reference consultation service in their library for distance learners and graduate students. This article outlines a practical approach for designing and initiating a virtual research consultation service pilot, providing equitable access to library services and a positive user experience for distance learners.
\end{abstract}

Keywords: virtual reference, virtual reference consultations, video reference, video chat, distance learners, online learners, video chat software

\title{
Introduction
}

Across academia, as administrators look to the future of their campuses, distance learners have increasingly grown as a proportion of enrolled students. Administrators are attracted to the low overhead and potential benefits of the economies of scale of online learning. Distance learners, who may be 'non-traditional' students, working full-time or returning to academia after a long absence, are attracted by the flexibility of an online degree (Brady, 2001; Boling, E. C., Hough, M., Krinsky, H., Saleem, H., \& Stevens, M., 2012). The Reference and User Services Association (2017) guidelines charge librarians to "[design] services that reflect the demographics, cultural diversity, and special needs of the [communities]" they serve and the Association of College and Research Libraries Standards for Distance Learning Library Services (2006) state that students "are entitled to the library services and resources of that institution, including direct communication with the appropriate library personnel, regardless of where they are physically located in relation to the campus; where they attend class in relation to the institution's main campus; or the modality by which they take courses." However, as online enrollments rise, libraries have struggled to meet the unique information needs of distance students, a task made more difficult by stagnant budgets, staffing shortages, the lack of training, and lack of knowledge about this population.

\section{Background}

The University at Albany (UAlbany) is not different. UAlbany is a four-year, R1 institution with approximately 15,000 undergraduate and 5,000 graduate students. (Fast Facts, n.d.). While primarily a residential campus, UAlbany has an increasingly large population of distance 
learners, including a highly-ranked online graduate program in Education. Several of its Colleges have fully online degrees, as well as hundreds of online courses interspersed throughout the catalog. In the University at Albany Libraries, there are over 60 professional staff and 26 support staff (Morris \& Roebuck, 2019). Virtual reference services, which launched in 2004, are limited to chat and email. After instituting a proactive chat model, through which a user is prompted by a chat invitation ("Ask Us!"), chat numbers doubled. Personalized Assistance with Searching (PAWS) research appointments, a popular one-on-one reference consultation service for oncampus students, are also offered. Students request PAWS appointments via an online form, provide details about their research topic, project, and course, then a librarian schedules an hourlong research consultation with them.

Chat and email reference services, while popular, do not allow for an in-depth, one-on-one consultation with a librarian as on-site research consultation services do. With the University's increasing number of online courses, the Libraries looked to expand virtual reference services to include virtual research consultations. Using the PAWS service as a template, a working group explored virtual alternatives to in-person research consultations to develop and launch a pilot program. Consideration was given to the potential ways of marketing the service, to the process of requesting a virtual appointment, and to generating librarian interest as service providers. A working group selected, tested, and evaluated several well-known and cutting-edge programs for conducting video conferencing, identifying and purchasing the necessary equipment. Once a program was selected, they developed assessment surveys, created training documents, and organized in-person training sessions for librarians with live demonstrations and Q\&As.

The pilot's participants were limited to graduate students, primarily distance learners enrolled in online programs. In-person consultation requests at the UAlbany Libraries had risen since 2014, averaging 20\% growth each year per librarian-reported statistics. Additionally, in 2017, just before the working group formed, a newly established college resulted in a dramatic increase in traditional in-person appointments from - a $700 \%$ increase in the fall of 2017 . If this trend continued, it would be difficult to balance in-person consultations with the possibility of a large influx of virtual consultations, thus the choice to limit participation in the virtual service.

This article documents the journey from idea to implementation, laying out the philosophical case for virtual reference consultations and exploring the feasibility of supplementing chat reference with virtual consultations by using video conferencing to connect with distance students. It details the process used to conduct a needs analysis of stakeholders, test software, and plan outreach and marketing strategies. The article also discusses issues and concerns (i.e., scalability, staff training, marketing, hours, etc.), the assessment data collected through postconsultation student surveys and librarian feedback, and practical tips for adapting, planning, and implementing this service at other libraries. 


\section{Literature Review}

According to the Department of Education's National Center for Education Statistics (NCES) (Ginder, Kelly-Reid, \& Mann, 2019), in 2017, 15.4 percent $(3,104,913)$ of the total enrolled students were registered exclusively in distance education courses and 17.6 percent $(3,552,651)$ were enrolled in some distance courses. Even as these numbers have risen, retention rates have long been an issue that plagues online education (Brady, 2001; Carr, 2001; Rovai, 2003). Online education programs attract a higher percentage of nontraditional students, who are statistically less likely than traditional students to complete their degrees (Rovai \& Downey, 2010). Bean and Metzner's definition of non-traditional students, though dated, is one that resonates particularly well when considering distance education. They defined a non-traditional student as a student who is "older than 24 , or does not live in a campus residence (e.g., is a commuter), or is a parttime student [and] is not greatly influenced by the social environment of the institution" (Bean \& Metzner, 1985, p. 489).

Studies have shown that nontraditional students' persistence rates are typically lower and the completion rates for online courses can be as much as $10-20 \%$ lower than those for traditional courses. Distance students are more likely to experience isolation from faculty, other students, and campus support resources, all factors that contribute to a sense of community on a college campus. (Carr, 2000; Rovai, 2002; Rovai \& Downey, 2010) Students value personalized feedback and communication from faculty members (Boling, et al., 2012; Rovai, 2002). They also value the community aspect of brick-and-mortar classrooms, reflected in their stated preference for the social aspects of their online classes, according to a case study from Boling et al (2012), who interviewed 10 students who had completed online degrees and five online instructors. They note that "students reported feeling disconnected with their instructors, the course content, and their fellow classmates" (Boling, et al, 2012, p.120) in courses that contained limited opportunities for interaction. When they surveyed students about their favorite activities, students described assignments that required them to text fellow students or interact with others in their own communities, which suggests that their concept of community can be broad, so long as it exists.

Additionally, data suggest that students with a blended course load (hybrid and traditional classes) have a higher retention rate than those who take only online courses and even a slightly higher retention rate than those who take only traditional classes. James, Swan, \& Daston (2016) examined Predictive Analytics Reporting Framework data which included over 650,000 students records at five primarily onground community colleges, five primarily 4-year universities, and four primarily online institutions. Even when controlling for age, gender, type of institution, and economic status (indicated by the receipt of a PELL grant), students with a blended course load were retained a higher rate. Data were limited by number of institutions, but it certainly suggests the importance of flexibility to student retention and success. 
CAN YOU SEE ME NOW?

\section{Libraries and Distance Students}

There is little literature specifically addressing the library's impact upon distance students' retention rates, however, librarians have long argued that library usage is connected to student retention (Kramer \& Kramer, 1968). One of the questions continually raised in the research on this topic is: how can researchers prove causation? Some articles suggest that there is an anecdotal connection between the library and student retention (e.g., virtual reference and retention and even working in the library and retention) (Bell, 2008; Gaide, 2004). Other articles have made the connection between variables such as general self-reported library usage and student retention or between library expenditures and retention (Bell, 2014; Rushing \& Poole, 2002).

Research has suggested a positive correlation between certain library information resources (e.g., using the physical and online collections and studying in the physical space and first-year retention and student GPAs) (McCarthy, 2017; Soria, Fransen, \& Nackerud, 2013; Stemmer \& Mahan, 2013). Librarians, particularly those at predominantly or solely online institutions, are clearly interested in exploring the correlation between libraries and online student retention but this proves difficult when a student only has virtual interactions with the library. This research is further compounded by the difficulty in proving causation (Needham, Nurse, Parker, Scantlebury, \& Dick, 2013).

Research also suggests that the hours in which library services are offered affect whether distance students can even make use of them. Even as libraries attempt to make all services available to distance learners, local resources may be more effective, whether it be because of technical challenges or the learning curve associated with accessing and learning to effectively use library resources at one's home institution (Buck, 2016). Rovai (2002) suggests that libraries and the skill-sets often taught in information literacy sessions are particularly useful to online students, noting that because they "largely work independently, they also need the information literacy skills to 'recognize when information is needed and have the ability to locate, evaluate, and use effectively the needed information"'(p. 10). Unfortunately, without a concerted effort at marketing and outreach, awareness of library resources is often low among distance students (Sullo, Harrod, Butera \& Gomes, 2012).

\section{Exploring Virtual Reference in Libraries}

The existing literature on virtual consultations is light on the ground in the Library and Information Science field (Bennett, 2017). Virtual reference has long been synonymous with chat reference. In fact, database searches for "virtual reference" yield very few results for articles

related to one-on-one virtual synchronous reference consultations but produce a bevy of references to chat and email reference. There is not yet one standard definition for the virtual synchronous one-on-one research consultations that UAlbany offers in the literature, but in their study, Maddox and Stanfield (2019) define research consultations by differentiating them from 
unscheduled reference transactions, such as chat reference sessions. This distinction is an important one, so for the purposes of this article, virtual consultations will be defined as previously scheduled one-on-one virtual synchronous research consultations. As of this writing, Maddox and Stanfield's study is one of the first surveys of librarians that conduct virtual reference consultations. After a comprehensive literature review, they surveyed 232 librarians, primarily from four-year colleges and universities. Of this number, 136 (59\%) offered virtual reference consultations. They queried respondents on the number of consultations, institutional policies, the software used, and individual experiences with conducting consultations. Interestingly, 128 or $94 \%$ of respondents who offered virtual research consultations indicated that there was no overarching library policy regarding such consultations.

Much of the literature is limited to the use of videoconferencing software in delivering online instruction, not reference consultations, but pieces of useful information exist in these articles, with regard to identifying concerns to explore when planning a pilot, such as staff training, potential technical issues, and student concerns. For example, librarians at Montana State University (MSU) chiefly used web-conferencing software for real-time online information literacy instruction, but they found that web conferencing improved research consultations for their distance learners, as it made it possible to demonstrate database searches on the screen. MSU librarians noted that technical issues were the main problem they experienced but proffered suggestions for best practices gleaned from three years of online teaching. While some suggestions are not applicable to virtual consultations, others, such as keeping sessions under one hour, emailing student surveys after the session, and emailing a link to session recordings are helpful (Bonnand \& Hansen, 2012).

Staff training and availability were other concerns seen in the literature. One article stressed the importance of staff training and ensuring librarians are comfortable with the technology (Lietzau \& Mann 2009). Another article, detailing the implementation of a virtual consultation service at Missouri State University, seemed to stress a similar concern. The author noted that, at their library, virtual research consultations were conducted by their e-learning librarian because that librarian was comfortable teaching online (Bennet, 2017). One article noted that, according to feedback from synchronous webinars, convenience was a huge factor for their students (Moorefield-Lang \& Hall 2015). Given that students' schedules, particularly those of nontraditional students, do not always line up with the average librarian's schedule, this may be a concern.

The literature was divided on recording capabilities, much like with chat transcripts. Some articles viewed this as a useful feature (Moorefield-Lang \& Hall, 2015), while others noted that students never requested the video from their instruction sessions or consultations (Bennett, 2017). 
Some libraries have offered something akin to virtual reference office hours (Arvin \& Kaiser, 2012). Another library offered virtual synchronous reference consultations, but due to worries about student comfort and privacy, most of their sessions were live audio and chat, not video, although the author noted that in a session where a student activated their webcam, the librarian conducting the consultation said that the ability to see nonverbal cues was helpful. Though they were teaching online information literacy classes, not offering virtual reference, Barnhart and Stanfield (2011) raised an interesting point: rather than trying to precisely recreate on-campus services, maybe librarians should consider that "the same level of service will look completely [different] when it is delivered online" (p. 64).

\section{Pilot Study Methodology}

The working group organized a pilot study (i.e., a small-scale, time-limited launch), comprised of four reference librarians representing each of the UAlbany campus libraries: two Subject Librarians, a User Experience Librarian, and a Marketing and Outreach Librarian. The group gathered input on research consultations from user groups to guide the development of the pilot. They reviewed and tested four software products and apps to determine the best application for a virtual consultation program. Reference librarians were invited to participate in the pilot, and inperson training was provided prior to launch. The pilot was available to students enrolled in UAlbany's 15 fully online degree programs. Students who registered for one or more fully online courses but were enrolled in a traditional degree program fell outside the scope of the pilot.

\section{User Attitudes, Suggestions, and Preferences}

The working group collected feedback from multiple library user groups regarding virtual consultations to guide the structure of the pilot. The groups included, students who participate in the in-person service, the Student Advisory Board (SAB), a focus group comprised of both graduate and undergraduate students from a variety of academic programs, subject librarians who provide research consultations, the faculty and directors of online-programs, and an anonymous, open poll made available on the library website.

Students generally indicated that they found the Libraries' reference services helpful and specified that they prefer talking face-to-face. When interviewed after a PAWS research consultation, one undergraduate senior said, "I'd prefer meeting in person. I like being able to follow along as you search. I think [virtual consultations] would be useful for a day like Monday [snow delay], or if someone is unwilling or unable to come to campus."

Student feedback from the Student Advisory Board (2017) seemed situational. Only three of eleven students were familiar with the in-person service. One student emphasized the need for flexibility, explaining that working full time during the day left them unable to come to the library for an in-person meeting. Students also noted that virtual consultations could reduce commuting and preferred a service that was supported on mobile devices. "Mobile compatibility 
would help because you don't have to factor in travel time" and a virtual service "would be helpful for those who don't have a laptop." A third student liked the idea because "you don't have to be in the library and can get help from home or your dorm." Some students said they did not mind the daytime appointments, coming to the library, or were often in the library to study during the day. Four out of eleven students remarked that they liked working with librarians inperson. This supported the selection of a virtual conference software that allowed video conferencing as well as screensharing capabilities. Comments such as "During [the] snowy season, yes, not having to leave helps" and "My subject librarian is downtown, and I don't really like going down there. [I] would be open to a virtual meeting" indicated that the service could be attractive to on-campus students as well as off-campus students.

The working group sought feedback from the 26 public-facing reference and subject librarians via email and in-person meetings. Feedback about offering virtual consultations was generally positive, with a few reservations. Several librarians expressed concerns about the service's potential hours and the impact that weekend or evening consultations might have on their schedules and their ability to meet their regular daily duties. The Reference \& Government Information Librarian expressed support for the idea but stressed the necessity for staff training and practice with the software before going live.

The Subject Librarian for Social Welfare and Research Impact already conducted virtual consultations with students in their subject area and considered it a useful, positive service. They contributed feedback to the working group about best practices in conducting virtual sessions. The Librarian for Business \& Economics noted that "this kind of service would be useful to students in my subject areas. It may be slow to start, but I can envision it becoming popular once it's well known." As a result, training sessions were conducted and best practices documentation was compiled.

Feedback was collected from faculty and directors of online programs by email. A faculty member from the School of Public Health indicated that a service like this would be very valuable for students in the School of Public Health which is located on a campus without a designated library building. The Director of Online Education for the School of Public Health was very interested in the service. "This sounds like a great opportunity for students and I would be interested in including our online student body as part of this pilot initiative." They provided helpful statistics on the online student body, adding "I would anticipate only a small fraction of the 99 [enrolled] students to actually take advantage of it." (B. Kirkwood, personal communication, July 19, 2018) Such comments added perspective to the number of students enrolled and potential availability of those who might participate in the pilot.

The Assistant Director of the Information Science School Library Program commented "this is a great opportunity, and I would love to assign students this as a required activity during our 
CAN YOU SEE ME NOW?

introductory course at the very least." (S. Mersand, personal communication, August 11, 2018) Due to concerns from Subject Librarians about the potential volume of appointment requests, the working group was hesitant to make virtual appointments part of a class assignment. However, this could be a future consideration for the service.

In response to concerns about staffing, hours, and scalability, the working group added an anonymous poll to the library website to collect information on the time of day students preferred to meet with librarians. 57.14\% of respondents indicated that their preferred time for an appointment was between 8:00 a.m. - 12:00 p.m., 28.58\% preferred 5:00 p.m. - 9:00 p.m. and $14.29 \%$ preferred 12:00 p.m. -5:00 p.m. This information led the working group to recommend running a limited pilot during regular service hours and using reference statistics from the 2018/2019 academic year to reevaluate staffing and service hours.

\section{Software Review}

The working group identified common video conferencing features and prioritized them based on the charge, the literature, and the experience gleaned from providing in-person PAWS research consultation appointments. They identified as the highest priority features: audio, video, chat, desktop sharing, file sharing, file upload, cloud-based meeting attendance (at least from the patron end), and mobile device support (specifically, the ability to attend meetings from mobile devices). Other features such as cobrowsing, recording capabilities, whiteboards, and the ability to host a meeting from a mobile device were noted as useful features but were accorded a lower priority.

Applications that met the requirements included Join.me, GoToMeeting, Slack, and Skype Business. The UAlbany Libraries had subscriptions to Skype Business and GoToMeeting and acquired trial subscriptions to Join.me and Slack. The testing environment was based on the current requirements for online-programs. The only technical requirement set by the university for students enrolled in fully online degree programs was to have access to a computer with highspeed internet (UAlbany, Department of Online Learning, 2019). The working group tested each service by calling an external volunteer to simulate the likely conditions of a virtual consultation (i.e., a student using a webcam on their personal computer while connected to a home wireless network with high-speed internet) as well as to test each of the eight features previously identified as high priority, such as sound quality, connectivity, and ease of use. They also tested the applications' mobile capability and features. Based on the tests, Join.me was recommended for the pilot program (Table I).

\section{Recommended}

Join.me. Join.me is the only service that did not require the user to install software when joining a meeting. The librarian initiating the meeting may download a plugin or, if using a mobile device, install the Join.me application. However, any users joining the meeting may do so via a link, even when joining with a mobile browser. During the test, the sound quality was 
excellent on both computers and mobile devices. The software was quick to load and easy to navigate. The screen-sharing, audio, and chat features were easy to use and intuitive, and the function windows could be stacked, allowing librarians to share their screens, chat, and still see the patron's webcam window.

The free version of Join.me was tested, but the Outreach and Marketing Librarian found additional features in the paid subscription, such as creating a branded experience for library patrons, which made it worth the subscription price. The paid version also included features such as Outlook \& Google Calendar plugins and the ability to customize the meeting URL (i.e., https://join.me/PAWS vs https://join.me/367-929-157) and the background image, which would allow branding the service following university brand guidelines. Under their nonprofit pricing plan, the paid version of Join.me was \$13/month for one simultaneous user ("Do good. Better," n.d.)

\section{Not Recommended}

Slack. The working group concluded that they could not recommend Slack. They found several of Slack's features, such as its appealing interface, strong chat features, and channels or "breakout rooms", useful. Unfortunately, poor video integration (i.e., requiring users to download a plugin and toggle between chat and video windows) left the application ineligible for use in the pilot program. Further, users must have a paid account to access the screenshare features through a connecting app called Screenhero. If Slack develops an integrated screenshare feature, it may be a viable option in the future.

Skype Business. Skype Business, formerly Lync, was actively discouraged. It was tough to set up and begin a consultation session during the testing. The test user experienced difficulty connecting to the meeting, the meeting app took a long time to load on the librarian's screen, the chat and video integration was not intuitive as noted by both the user and the operator, and the test user remarked that the sound quality seemed poorer compared to that of other applications.

GoToMeeting. GoToMeeting was acceptable. It included all the features the working group identified as a priority, including a relatively simple, intuitive interface, and very good sound quality. However, it required users to download an application to their phone or computer to join meetings. This would be a hurdle to overcome as not all users have the ability to download software, whether they are using a public workstation or a device with limited storage capacity.

\section{Implementing the Pilot Program}

\section{Staff Training and Setting Service Hours}

Staff expressed concerns about the potential for online students to request appointments outside business hours. As previously mentioned, an anonymous survey was created and placed on the 
PAWS research consultation request webpage to collect data about users' preferred appointment times. The survey results indicated a 30\% preference for hours beyond business hours and the SAB suggested later hours would be valuable. Due to the pilot program's limited duration and scope, as well as limited participating staff, the working group decided to roll out the service with the same hours and policies as the current 9:00 a.m. - 5:00 p.m. PAWS research consultation hours. To provide some flexibility, librarians could make their own scheduling exceptions when picking up appointment requests.

The working group recommended a comprehensive training program for librarians, including training sessions, a how-to guide for the web conferencing software, best practices for video conferencing, and practice consultations. They built an internal LibGuide that walked the participating librarians through the steps of scheduling and hosting a virtual consultation through the Libraries' Join.me account. It included instructions on the technical specifications and on hosting from a laptop or library computer. Two workshops were scheduled over the summer, inviting all the reference librarians to learn about the pilot program and volunteer to participate if interested. The workshops were extended to subject librarians who might find the software application useful for working virtually with students in associated Ph.D. programs. In total, seven librarians attended. Questions about scheduling appointments were raised. To address these potential issues, a section outlining how to schedule appointments, including the use of Outlook apps to connect with Join.me, was added to the LibGuide.

\section{User Specifications}

Patrons' digital ease of access to virtual research consultations was a top priority, so that they would have a seamless and positive user experience. As previously mentioned, students enrolled in fully online degree programs are required to have access to a computer with high-speed internet. Though Join.me requires no software download for patrons to join a meeting, given that technical issues were the main complaint from the libraries in the literature and from the experiences of the Subject Librarian for Social Welfare and Research Impact, who regularly provides this service to their students, the working group recommended taking steps to minimize potential tech-related issues. They determined that the minimum user specifications for the selected software must be communicated to patrons either on the research consultation appointment form, in the appointment confirmation email, or both. Due to the limitations of the form, the minimum user specifications were included in the request email confirmation.

To help ensure a positive experience, general best practices and recommendations for video chatting (e.g., removing ambient noise that can be picked up by a microphone, using broadband internet, being cognizant of light sources and backgrounds, testing webcams, etc.) were communicated to the librarians and patrons prior to the consultations.

\section{Equipment and Space Planning}

The flexibility of Join.me to host a virtual meeting from a mobile device was attractive but not practical for a virtual research consultation. Testing found the mobile devices' smaller screen sizes made it difficult to toggle browser windows, share screens as a host, or use the whiteboard 
feature. The librarians were asked to host meetings from desktop computers or laptops. To provide a consistent space that guaranteed the software and PC technical requirements, two of the dedicated PAWS consultation rooms were fitted for virtual consultations. This included requesting and purchasing a dedicated webcam with a built-in microphone for each space.

\section{Marketing}

Based on the comments from librarians, student focus groups, the literature, and input from the Outreach and Marketing Librarian, the working group decided to marry the current marketing strategy for research consultations with the rollout of this additional service. Hansen and Bonnand (2012) noted that lack of awareness and perceived access difficulty were two of the main reasons online students did not use library resources. The librarians noted that many of their online students did not realize they could remotely access resources, and others perceived that using library databases would be much harder than using the open web. The SAB echoed this theme. When asked about the PAWS service, only three SAB members had heard of it, and none had used the service, even though many of the students said that they find librarians helpful and have had positive interactions with them in the past. Of particular interest, the students all agreed that the reference consultation service's name was confusing, and it was clear to the librarians that they did not understand the purpose of the service. (Student Advisory Board, 2017)

The pilot program was directly marketed to instructors who teach online courses while reaching out to staff contacts in online degree programs, such as the Instructional Designer for Online Teaching and Learning, and reaching out to staff in Information Technology Services to pursue Blackboard LMS integration. The Office of Online Teaching and Learning's Instructional Designer for Online Teaching and Learning agreed to consult with the libraries for the pilot. (D. Hamilton, personal communication, June 14, 2018) Updating the Libraries' Services for Online and Distance Learning and the Research Assistance webpages and making them more discoverable was also recommended.

The PAWS research consultation appointment request form was updated to include a drop-down menu option asking students if they were enrolled in a fully-online degree program (yes or no). If students responded yes, a menu of questions was presented asking if they would be interested in scheduling a virtual consultation. If a student requested a virtual consultation, an email would be distributed to the participating reference librarians with the subject line: Virtual PAWS appointment request from [patron name].

\section{Assessment Tools}

The Libraries used Desk Tracker Basic to track and analyze the statistics from PAWS research consultations, with data dating back to 2013. The User Experience Librarian reviewed Desk Tracker Basic to determine the best way to add a new service to the current statistic reporting. For on-site PAWS research consultations, information such as the cooperating librarian, the meeting location, and the date and time of appointment was tracked. Additionally, virtual consultations were incorporated into the existing assessment for on-site PAWS research consultations. The current statistics reporting form was modified to note and track virtual 
consultations, with additional reporting features added to capture missed appointments and other time and location issues unique to virtual meetings. Additional reporting training was not necessary for current users. In addition to recording typical demographic data about students (e.g., designated campus, program they are enrolled in, course instructor's name), a postconsultation assessment survey tool included measures to assess student satisfaction, confidence, and reasons for selecting a virtual consultation.

\section{Discussion}

\section{Results}

\section{The Pilot (November 2018 - August 2019)}

The virtual service pilot ran from November 2018 to August 2019 and yielded four participants, referred to as Participant A, B, C, and D. The participants requested a virtual research consultation using the appointment request form which was designed to offer a virtual appointment option only for students enrolled in a fully-online degree program. Participants C and D scheduled appointments but did not follow through.

Participant A was a part-time returning masters-level graduate student studying curriculum development and instructional technology; the distance from campus factored into the need for making a virtual appointment. When asked how they heard about the service, they stated "other," citing an email sent from the libraries. Participant A stated that they were at the beginning of their program and mostly needed an overview of e-resources and basic library instruction, though they did say they were making the appointment in conjunction with a specific Educational Theory and Practice course they were enrolled in that semester. In-person consultations are usually an hour, though given the setup time needed for meeting online, the total appointment time was closer to seventy minutes. The software worked well. The participant opted not to utilize a web camera, though it is unclear whether this was by choice or because they did not have one available. Participant A provided feedback about their experience, stating that they felt that the session was well-tailored to their specific needs and topical area. They also felt that the entire appointment process (ease of use, scheduling, connecting, etc.) was extremely easy with no complications. The librarian conducting the appointment also provided feedback, noting that it would be helpful to have a canned introduction script to begin the appointment as well as a research plan that can be provided beforehand so the student can take notes; currently there is a research plan for in-person consultations, which students can print and bring to the appointment or that is provided at the start of the appointment.

Participant B was a doctoral student studying sociology; the distance from campus was also a factor in the need to make a virtual consultation appointment. This student was on-campus in their office for this meeting but wanted to test the service to ensure it was something they could use while traveling. When asked how they learned about the service, they said they heard about it from a librarian. The appointment was sixty minutes in length and was completely guided by the librarian; they discussed potential journals for publication, open access journals, copyright, and author's rights. Both the participant and the librarian used a webcam and audio. The librarian 
conducting the appointment made sure to arrive twenty minutes early to setup; this wound up being a good practice because the computers used for these appointments had updated, and Join.me was no longer available on them. Once the software was downloaded again, the setup and connection went smoothly, and the student was able to connect without hassle. During the appointment, there was one point where the participant expressed difficulty reading the screen being shared, but they let the librarian know, and the librarian was then able to zoom in using their browser. Participant B provided brief feedback on the appointment, stating that they found the kinds of tools they were shown to search for assistance in seeking publications helpful. Participant B did not offer any feedback about the ease of use, scheduling, or connecting using the virtual platform. The librarian conducting the appointment also provided feedback, stating that the session went well, and that it was helpful to see the person the appointment was with; it felt more intimate than a phone call or regular online chat. The librarian also stated that they felt that if this appointment were conducted via written chat, they would not have been able to provide as much detail as they did during this appointment.

Participant $\mathrm{C}$ was a graduate student in the Master of Public Administration program and based in the greater NYC area. They sought a general introduction and a refresher on searching for journal articles and search strategies. This participant rescheduled twice, but ultimately did not follow through. However, it was important to include information about this participant because it demonstrates further interest in the service. When asked how they learned about the service, they stated that they found the information on the Libraries' website. As aforementioned, this participant did not follow-up to hold the appointment, though they were enthusiastic about the prospect of participating virtually. It is possible that extended service hours might have helped this student. Although the appointment was not kept, the responsible librarian could still provide feedback for some of the process' more technical aspects. The librarian was able to customize the Join.me email invitation to make it more personalized. They also commented on the lighting for the appointment space.

There is limited information regarding Participant D other than their status as a graduate student in the Master of Public Administration program. They heard about the service from the Libraries' website. They scheduled a virtual appointment for citation assistance, stating that the appointment was needed for various courses. Before the appointment, the participant emailed the librarian to say they scheduled a meeting with their professor and no longer needed the appointment.

\section{Limitations and Challenges}

Currently, in-person consultations are scheduled between 9:00 a.m. and 5:00 p.m., Monday through Friday. Due to limited staffing availability and the lack of dedicated staff solely for virtual services, it was decided to offer virtual appointments during the same hours. This restriction could account for the lack of appointments. In retrospect, limiting the service's hours so severely during this pilot was completely unnecessary. As previously stated, nontraditional students may have personal or professional commitments that make it harder to schedule appointments during normal operating hours. These same students may also prefer appointments on the weekends, which are not currently offered for either service. 
Since the target group for this rollout was primarily distance learners, marketing the service proved difficult. Outreach was done at campus fairs geared toward faculty and at meet-and-greet faculty outreach events held by the libraries. Communication at these events consisted of one-onone discussions and branded print postcards for the service. Communication to targeted faculty members that taught or had connections to online students were also sent via email. The onus was then placed on the ability of the teaching faculty and office administrators to share this information about the service with their students rather than the library marketing directly to the students that would use the service. Also, because this service is being provided to distance and online learners, the opportunity for word-of-mouth marketing - the way many library services succeed in becoming popular among students — was lost (Barber \& Wallace, 2010).

\section{Continuation of Service}

At its conclusion, the pilot program was deemed a success despite the low participation.

Enthusiastic responses from librarians who were trained and who conducted virtual consultations along with the positive feedback from Participants A and B, and a positive response from administrators demonstrated the value this service held. Technically, the pilot ran smoothly without issue. Modifying the appointment request form and the librarian assessment form to accommodate virtual appointments was simple. Librarians who were trained to provide the service felt confident initiating meetings and the software served both librarians and patrons as expected. To everyone's relief and confusion, staff were not overwhelmed with consultation requests.

In their 2012 Internet \& American Life Project, the Pew Research Center polled internet users between the ages of 12 and 17 years old and found that over one-third of the respondents participated in video chats using applications such as Skype, Google Talk or iChat (Lenhart, 2012). According to Facebook, video chats among their users more than doubled from 2016 to 2017, reaching "17 billion [real-time] chats" (Kelly, 2017), and these statistics only encompass video chat using Facebook's interface. Apple's FaceTime reportedly recorded over 15 million daily video chats in 2014 (Clover, 2014). When one considers what these percentages might mean in real numbers, this is staggering. Librarians can comfortably assume that the majority of these video chats have nothing to do with library research. However, the reality remains: the population is increasingly growing used to real-time video chat, and libraries should explore the opportunity to reach out to users using this medium.

Even though the pilot yielded few participants, it is important to provide multiple avenues for distance learners to engage with the libraries and librarians. In his persistence model, Rovai synthesized several distance education models and research, illuminating several relevant factors relating to persistence in online education. While there is no one way to ensure adult persistence, he suggested early intervention that considers internal and external factors, such as bolstering a sense of community, flexibility with scheduling, flexibility with travel requirements (i.e., driving to campus). Some of his suggestions for early intervention to increase persistence rates with 
online students dovetail nicely with virtual resource consultations (e.g., bolstering a sense of community with face-to-face virtual meeting with a librarian) (Rovai, 2002).

Despite the available technology and the dire pronouncements that Google will soon replace librarians, students still value face-to-face reference interactions (Butler \& Byrd, 2016; Faix, MacDonald, \& Taxakis, 2013; Magi \& Mardeusz, 2013). While the literature suggests there is a logical link between video consultations, the creation of community for online students, and retention, the pilot's sample size is too small to be conclusive. However, offering virtual reference consultations may not only provide equitable service to distance students but foster a sense of community to support their retention.

\section{Future Implementation}

During the research phase for this pilot, LibraryH3lp was the Libraries' primary virtual chat platform. This platform did not have a video chat feature which led to the exploration of others. Since then, the Libraries have switched to Springshare's LibAnswers, which offers built-in video chat and screensharing using Zoom. In the future, using Springshare's Zoom add-on to offer virtual consultations may be a possibility, eliminating the need to pay for an additional software service.

The marketing of the service is likely to shift. Currently, emphasis is placed heavily upon targeting online teaching faculty to share the existence of the virtual consultation service with their students. In the future, exploring ways to directly market to intended audiences without the use of a middleman would be beneficial. Possible avenues to explore are electronic word-ofmouth (eWOM) through social networking platforms, email listservs for online students, postcard mailers, and embedding the service into the university's online learning platform (Kalam Siddike \& Kiran, 2015).

Future options for continuing this service are varied. Partnering with specific online classes would provide an opportunity for us to work with a captive audience, allowing us to provide outreach about the service directly to a known group of students and their instructor(s).

Expanding the service's hours, even if only for an additional hour in the morning and evening, could provide a little more flexibility in accommodating graduate student schedules. Removing the limitation on who can participate and opening the service to all graduate and undergraduate students is an option, though this may tax limited staff if the service were to become more popular.

\section{Conclusion}

This study investigated the question of how to provide equitable reference services to distance students. The literature suggests that virtual research consultations are an asset to library services and help to provide equity of service to all students. The overall conclusion from this pilot is that offering virtual research consultation is a valuable option to distance students and potentially to all students, no matter their location in relation to campus. Librarians who participated in the 
CAN YOU SEE ME NOW?

pilot virtual service were satisfied with the training and ease of hosting appointments, and the flexibility to be able to conduct research consultations virtually. Students who participated in interviews and in the pilot saw value in connecting with librarians virtually. As social video chatting increases among users and online education becomes more popular, continued growth in virtual library services can be expected. Including a virtual research consultation service can be affordable simple, and quick to implement as modelled. Having a framework in place puts the libraries in a good position going forward should there ever be a time where offering virtual services becomes vital.

In addition to providing more equitable service to distance students, initiating a virtual consultation service now allows librarians the opportunity to ease into this service/expand their service offerings/become more proficient with virtual reference consultations and position their libraries ahead of future/projected demand.

\section{References}

American Library Association. (2006, September 1). Standards for Distance Learning Library Services. Retrieved September 24, 2019 from: http://www.ala.org/acrl/standards/guidelinesdistancelearning

American Library Association. (2007). Professional Competencies for Reference and User Services Librarians. Retrieved from http://www.ala.org/rusa/resources/guidelines/professional

Arvin, S., \& Kaiser, A. (2012). Case study of synchronous virtual reference in an academic library. Internet Reference Services Quarterly, 17, 83-93. https://doi.org/10.1080/10875301.2012.718317

Barnhart, A., \& Stanfield, A. (2011). When coming to campus is not an option: Using web conferencing to deliver library instruction. Reference Services Review, 39, 58-65. https://doi.org/10.1108/00907321111108114

Barber, P., \& Wallace, L. (2010). Building a buzz: libraries and word-of-mouth marketing. American Library Association. 
CAN YOU SEE ME NOW?

Bean, J. P., \& Metzner, B. S. (1985). A conceptual model of nontraditional undergraduate student attrition. Review of Educational Research, 55(4), 485-540. https://doi.org/10.3102/00346543055004485

Bell, S. J. (2008). Keeping them enrolled: How academic libraries contribute to student retention. Library Issues: Briefings for Faculty and Administrators, 29(1), 1-4.

Bell, S. J. (2014). Retention matters, but it's not the only thing that counts: As higher education shifts its focus away from retention toward graduation, librarians are seeking new ways to connect with students and ensure their success. Information Outlook, 18(1), 11-14.

Bennett, J. L. (2017). Virtual research consultations study. Internet Reference Services Quarterly, (22)4, 193-200. https://doi.org/10.1080/10875301.2017.1305475

BestColleges. (2019, April 15). Most common reasons for choosing online versus on-campus learning options according to online students in the United States in 2018 [Graph]. In Statista. Retrieved September 13, 2019, from https://www-statista-com.libproxy. albany.edu/statistics/731089/reasons-why-students-chose-online-versus-on-campusdegree-programs/

Boling, E. C., Hough, M., Krinsky, H., Saleem, H., \& Stevens, M. (2012). Cutting the distance in distance education: Perspectives on what promotes positive online learning experiences. Internet and Higher Education, 15, 118-126. http://dx.doi.org/10.1016/j.iheduc.2011.11.006

Bonnand, S., \& Hansen, M. A. (2012). From Two Dot to Turkey: Reaching online library users via web conferencing. Urban Library Journal, 18(1), 1-13.

Brady, L. (2001). Fault lines in the terrain of distance education. Computers and Composition. (18)4, 347-358. 
CAN YOU SEE ME NOW?

Buck, S. (2016). In their own voices: Study habits of distance education students. Journal of Library \& Information Services in Distance Learning, 10, 1-37. https://doi.org/10.1080/1533290X.2016.1206781

Butler, K., \& Byrd, J. (2015). Research consultation assessment: Perceptions of students and librarians. The Journal of Academic Librarianship, (42)1, 83-86. https://doi.org/10.1016/j.acalib.2015.10.011

Carr, S. (2000, February). As distance education comes of age, the challenge is keeping the students. Chronicle of Higher Education, 46(23). Retrieved from https://www.chronicle.com/article/As-Distance-Education-Comes-of/14334

Clover, J. (2014, December 28). Apple Handles 'Several Billion' iMessages and 15 to 20 Million FaceTime Calls Daily. Retrieved from https://www.macrumors.com/2014/02/28/apple40-billion-imessages/

Do good. Better. (n.d.). Retrieved October 4, 2019, from https://www.join.me/pricing/nonprofit.

Faix, A., MacDonald, A., \& Taxakis, B. (2014). Research consultation effectiveness for freshman and senior undergraduate students. Reference Services Review. (42)1, 4-15. https://doi.org/10.1108/RSR-05-2013-0024

Fast facts. (n.d.). Retrieved from: https://www.albany.edu/about/about fastfacts.php

Gaide, Susan. (2004). Integrated library services boosts online recruitment and retention, Distance Education Report, 8(8), 1-4.

Ginder, S.A., Kelly-Reid J.E., \& Mann, F.B. (2019) Enrollment and Employees in Postsecondary Institutions, Fall 2017; and Financial Statistics and Academic Libraries, Fiscal Year 2017. Washington, DC: National Center for Education Statistics. 
CAN YOU SEE ME NOW?

James, S., Swan, K., \& Daston, C. (2016). Retention, progression and the taking of online courses. Online Learning Journal, (20)2, 75-96.

Kalam Siddike, M.A., \& Kiran, K. (2015). Marketing of academic library services through social networking sites: Implications of electronic word-of-mouth. Education for Information, 31(3), 143-159. https://doi.org/10.3233/EFI-150955

Kelly, S. (2017, December 13) Messenger's 2017 Year in Review. Retrieved from https://newsroom.fb.com/news/2017/12/messengers-2017-year-in-review/

Lenhart, A. (2012, May 3). Teens \& Online Video. Pew Research Center's Internet \& American Life Project. Retrieved from https://www.pewinternet.org/2012/05/03/teens-online-video/

Kramer, L. A., \& Kramer, M. B. (1968). The college library and the drop-out. College and Research Libraries, (29)4, 10-12. https://doi.org/10.5860/crl_29_04_310

Lietzau, J. A., \& Mann, B. J. (2009). Breaking out of the asynchronous box: Using web conferencing in distance learning. Journal of Library and Information Services in Distance Learning, (3)3, 108-19. https://doi.org/10.1080/15332900903375291

Maddox, J. J., \& Stanfield 1. (2019). A survey of technology used to conduct virtual research consultations in academic libraries. Journal of Library \& Information Services in Distance Learning, (13)3, 245-261.

Magi, T., \& Mardeusz, P. (2013). Why some students continue to value individual, face-to-face research consultations in a technology-rich world. College \& Research Libraries, (74)6, 605-618. https://doi.org/10.5860/crl12-363

McCarthy, S. C. (2017). At issue: Exploring library usage by online learner with student success. Community College Enterprise, (23)2, 27-31. 
CAN YOU SEE ME NOW?

Moorefield-Lang, H., \& Hall, T. (2015). Instruction on the go: Reaching out to students from the academic library. Journal of Library \& Information Services in Distance Learning, (9)12, 57-68. https://doi.org/10.1080/1533290X.2014.946347

Morris, S., \& Roebuck, G. (2019). ARL Statistics: 2016-2017. Washington, DC: Association of Research Libraries.

Needham, G., Nurse, R., Parker, J., Scantlebury, N., \& Dick, S. (2013). Can an excellent distance learning library service support student retention and how can we find out? Open Learning, (28)2, 135-140. https://doi.org/10.1080/02680513.2013.847364

Rovai, A. P. (2003). In search of higher persistence rates in distance education online programs. The Internet and Higher Education, (6), 1-16.

Rovai, A. P., \& Downey, J. R. (2010). Why some distance education programs fail while others succeed in a global environment. Internet and Higher Education, (13)3, 141-147. http://dx.doi.org/10.1016/j.iheduc.2009.07.001

Rushing, D., \& Poole, D. (2002). The role of the library in student retention. In M.C. Kelly \& A. Korss (Eds.) Making the grade: Academic libraries and student success (pp. 91-101). Chicago, IL: Association of College and Research Libraries.

Savage, D. (2015). The Perplexing Inattention to Research Consultations in Library Assessment Activities. In D. M. Mueller (Ed.), Creating Sustainable Community: The Proceedings of the ACRL 2015 Conference (pp. 577-584). Chicago: Association of College and Research Libraries. Retrieved from http://www.ala.org/acrl/acrl/conferences/acrl2015/papers

Soria, K., Fransen, J., \& Nackerud, S. (2013). Library use and undergraduate student outcomes: New evidence for students' retention and academic success. portal: Libraries and the Academy. (13)2, 147-164. https://doi.org/10.1353/pla.2013.0010 
CAN YOU SEE ME NOW?

Stemmer, J., \& Mahan, D. (2016). Investigating the relationship of library usage to student outcomes. College \& Research Libraries, (77)3, 359-375. https://doi.org/10.5860/crl.77.3.359

Student Advisory Board. (2017). 'Item 2.3: PAWS'. In Minutes of the Student Advisory Board 30 March 2017. University at Albany: University Library.

Sullo, E., Harrod, T., Butera, G., \& Gomes, A. (2012). Rethinking library service to distance education students: Analyzing the embedded librarian model. Medical Reference Service Quarterly, (31)1, 25-33. https://doi.org/10.1080/02763869.2012.641822

University at Albany, Department of Online Learning. (2019). How do I... Retrieved from [Redacted]

University at Albany. (n.d.). Online Learning at UAlbany. Retrieved from https://www.albany.edu/online-learning 


\section{Appendix}

\section{Software Review}
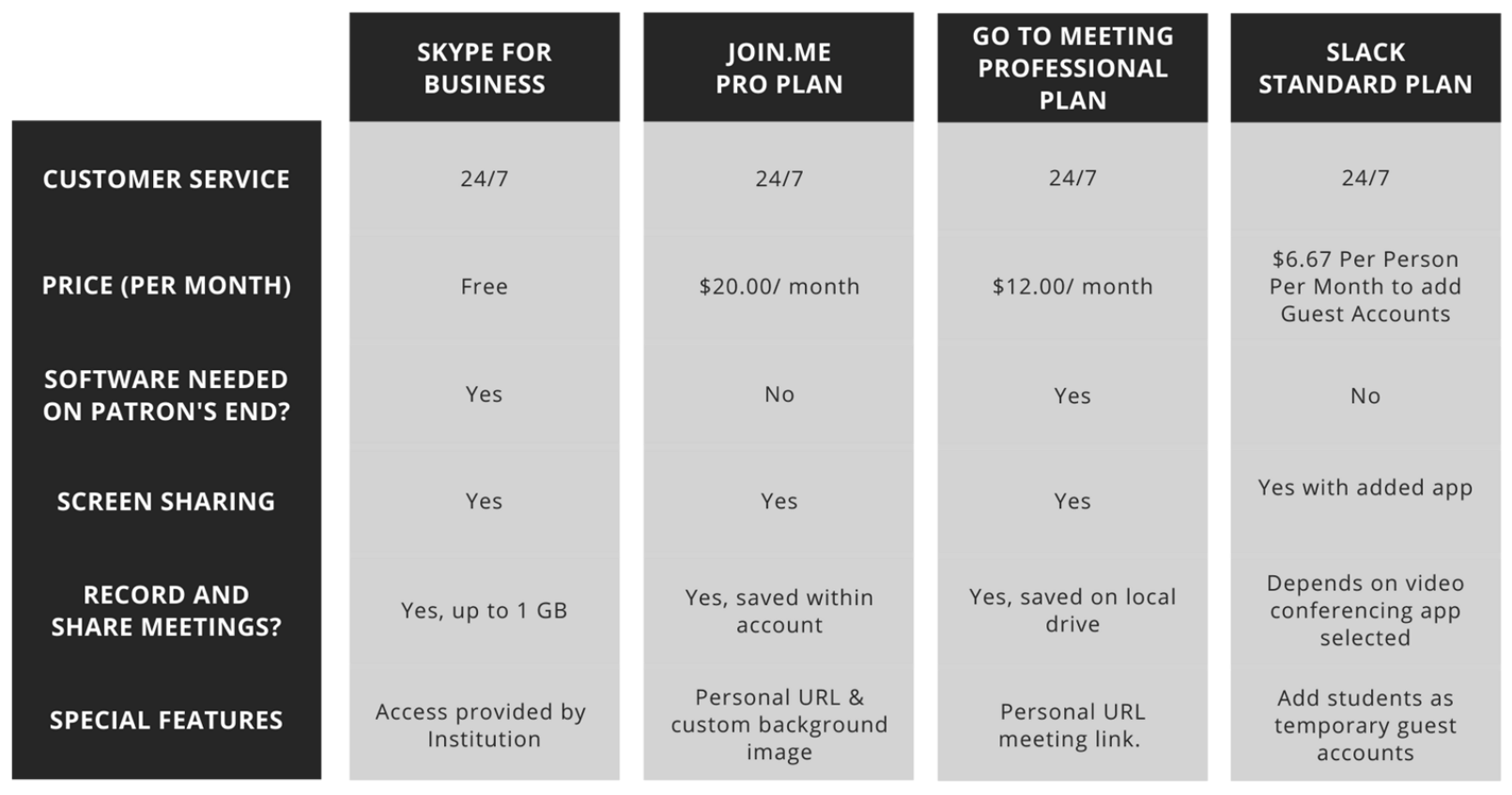

Table I. Software Review

Examples of virtual conferencing tools 